\title{
Pleural Infection Caused by Nocardia farcinica: Two Cases and Review of the Literature
}

\author{
Graciella Bagüeste $^{1}$, Jose M. Porcel ${ }^{1}$ \\ 1. Internal Medicine, Arnau de Vilanova University Hospital, Lleida, ESP
}

Corresponding author: Jose M. Porcel, jporcelp@yahoo.es

\begin{abstract}
Nocardia farcinica is a rare Nocardia species causing localized (lung, brain, skin) and disseminated infections. Predisposing factors include the chronic use of corticosteroids, organ transplantation and other immunocompromise conditions. Pleural empyema caused by this microorganism has scantily been reported. We describe two cases of pleural infection by $N$. farcinica that occurred in patients with a kidney transplant and cirrhosis, respectively. The first patient died soon after hospitalization, while the second survived nocardiosis (despite having significant adverse events to antibiotics) but eventually succumbed to other infectious complications. In this infectious disease, in which the duration of therapy is typically long and pleural space drainage is frequently required, bacterial susceptibility to antimicrobial agents should be tested.
\end{abstract}

Categories: Pulmonology

Keywords: nocardia farcinica, empyema, pleural effusion, antibiotics

\section{Introduction}

Nocardia farcinica is a particularly virulent Nocardia species that causes both localized and disseminated infections, mostly in the setting of immunocompromised conditions (e.g., glucocorticoids, calcineurin inhibitors and other immunosuppressive medications, hematologic and solid-organ transplant recipients, malignancy, HIV disease, diabetes). The infection is mainly acquired by inhalation, less commonly by direct inoculation through the skin, and frequently results in disseminated disease. In a Spanish series of 1,119 strains of the Nocardia genus, $N$. farcinica represented $11.4 \%$ of the isolates [1]. About $60 \%$ of $N$. farcinica strains were isolated from bronchial secretions, but only $4 \%$ from lung/pleural fluid samples [1].

Even though pneumonia is the most common manifestation of $N$. farcinica, pleural involvement is infrequent, with only a few cases being reported [2-14]. This article describes two additional patients with pleural empyema by this gram-positive aerobic actinomycetes and succinctly reviews the literature on the subject.

Review began 04/12/2021 Review ended 04/25/2021 Published 04/26/2021

(c) Copyright 2021 Bagüeste et al. This is an open access article distributed under the terms of the Creative Commons Attribution License CC-BY 4.0., which permits unrestricted use, distribution, and reproduction in any medium, provided the original author and source are credited.

\section{Case Presentation}

\section{Case 1}

A 73-year-old man was hospitalized for a two-week history of dyspnea. He had undergone a kidney transplant two years earlier and was taking prednisone $(5 \mathrm{mg} / \mathrm{d})$, tacrolimus $(2.5 \mathrm{mg} / \mathrm{d})$ and mycophenolate mofetil ( $1 \mathrm{~g} / \mathrm{d})$. A chest X-ray and CT showed multiple pulmonary nodules, some of which were cavitated, along with consolidations and a left free-flowing pleural effusion occupying about $25 \%$ of the hemithorax (Figure 1). A diagnostic thoracentesis displayed a non-purulent exudate with the following characteristics: erythrocyte count 38,500 cells/ $\mu \mathrm{L}$, leukocytes 987 cells/ $\mu \mathrm{L}$ (80\% neutrophils), lactate dehydrogenase $737 \mathrm{U} / \mathrm{L}$, glucose $95.5 \mathrm{mg} / \mathrm{dL}$, adenosine deaminase $14.4 \mathrm{U} / \mathrm{L}, \mathrm{pH} 7.30$ and C-reactive protein $133 \mathrm{mg} / \mathrm{L}$. Empiric antibiotic therapy with ceftriaxone and trimethoprim-sulfamethoxazole (TMP-SMX) was initiated. Subsequently, ceftriaxone was replaced by piperacillin-tazobactam. $N$. farcinica was isolated from the pleural fluid and blood cultures after eight days of incubation. The antibiogram showed that it was susceptible to TMP-SMX, linezolid, amikacin, imipenem and amoxicillin-clavulanate. Also, an active cytomegalovirus (CMV) infection was diagnosed based on the presence of CMV replication in the blood (240,000 copies $/ \mathrm{mL})$. Tacrolimus was discontinued because of its high blood levels $(13.35 \mathrm{ng} / \mathrm{mL})$. The patient died six days after hospital admission before any of the previous microbiological results became available. The autopsy confirmed the presence of bilateral pulmonary and pleural nocardiosis, as well as CMV pneumonitis; both entities probably contributing to death. 


\section{Cureus}

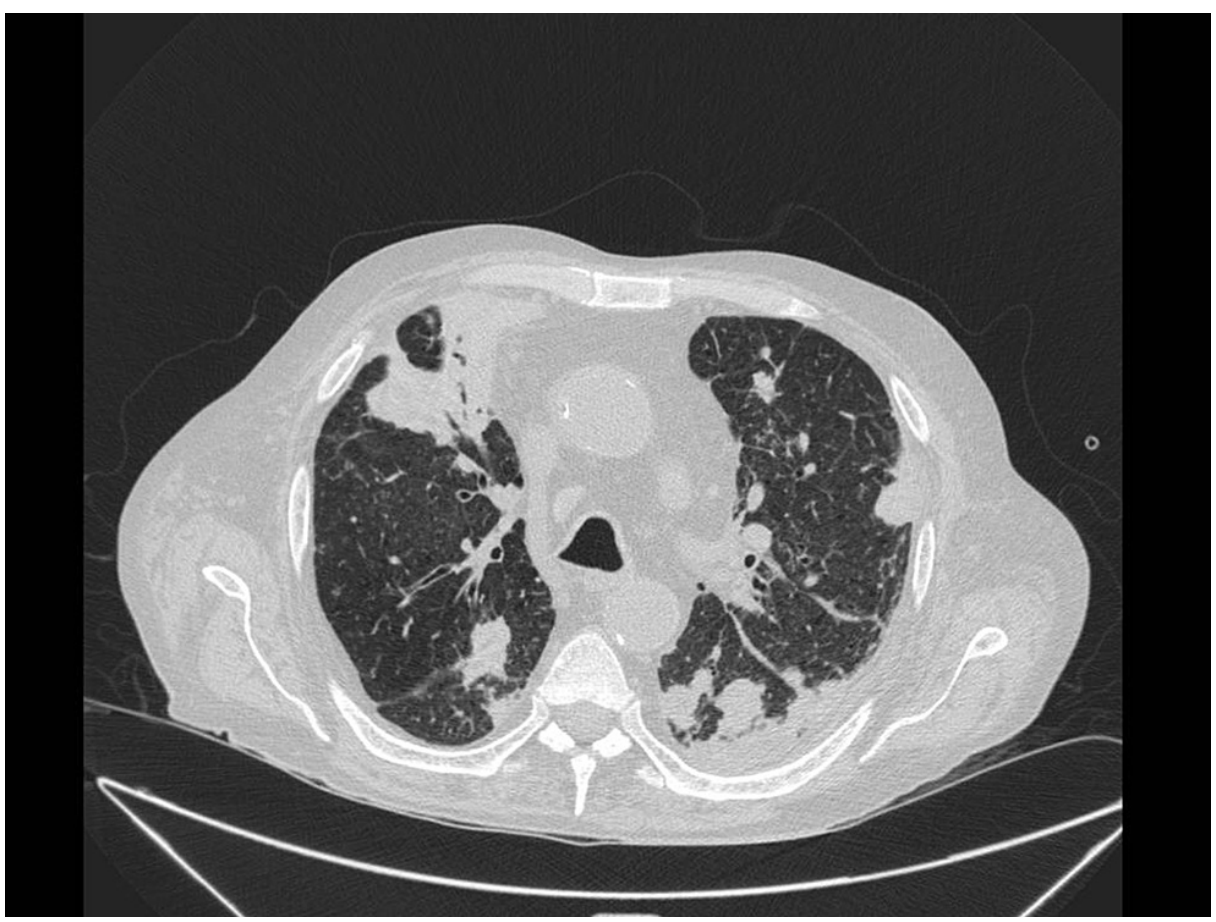

FIGURE 1: Chest CT scan showing pulmonary nodules and a left-sided pleural effusion

\section{Case 2}

A 49-year-old woman with a history of alcoholic liver cirrhosis (Child Pugh C and MELD score 19) was admitted to the hospital because of fever, dyspnea and right pleuritic chest pain of one-week duration. In some areas of ground-glass opacification, a large loculated right-sided pleural effusion and ascites were seen on the chest CT. A diagnostic pleural tap showed a non-purulent exudate with the following characteristics: erythrocyte count 34,900 cells/ $\mu \mathrm{L}$, leukocytes 2,411 cells/ $\mu \mathrm{L}$ ( $58 \%$ neutrophils), lactate dehydrogenase $595 \mathrm{U} / \mathrm{L}$, glucose $63.1 \mathrm{mg} / \mathrm{dL}$, adenosine deaminase $17.6 \mathrm{U} / \mathrm{L}, \mathrm{pH} 7.43$ and C-reactive protein $52 \mathrm{mg} / \mathrm{L}$. The analysis of peritoneal fluid was consistent with portal hypertension (serum-ascites albumin gradient $>1.1 \mathrm{~g} / \mathrm{dL}$ ). Empirical antibiotic therapy with cefotaxime was started along with two serial therapeutic thoracenteses of $600 \mathrm{~mL}$ each. $N$. farcinica grew on pleural fluid cultures after 6 days of incubation, but an antibiogram was not done. Blood cultures were negative. Cefotaxime was replaced by linezolid $600 \mathrm{mg}$ po q12h. One month later, the patient developed myelosuppression secondary to linezolid, which had to be withdrawn. At that time, there remained a small pleural effusion. The patient needed colony-stimulating factors (filgrastim), platelet and red cell transfusion. Ciprofloxacin (500 mg po q12 h) was initiated. After three months with the new antibiotic regimen, the patient suffered a cardiorespiratory arrest due to an acquired long QT syndrome that was attributed to fluoroquinolones. A long ICU stay (two months) was needed during which meropenem, vancomycin and fluconazole were administered for a number of infectious complications and cirrhosis decompensation. At hospital discharge, no further antibiotics were prescribed. One year later, the patient required a total right hip arthroplasty and died of septic shock secondary to an early-onset prosthetic hip infection.

\section{Discussion}

Pleural infection by $N$. farcinica is rare, with about 16 cases previously reported in the literature (Table 1), according to a PubMed search (keywords: [pleural or empyema or pleuritis] and Nocardia farcinica; time period from inception to March 2021) [2-14]. The general series of nocardiosis briefly mention a few additional cases of pleural involvement by $N$. farcinica, but with information so incomplete that they cannot be incorporated into this review.

\begin{tabular}{|c|c|c|c|c|c|c|c|}
\hline Reference & Age & Sex & Predisposing factors & Site of Infection & $\begin{array}{l}\text { Diagnostic } \\
\text { samples }\end{array}$ & Therapy & $\begin{array}{l}\text { Death due } \\
\text { to } \\
\text { nocardiosis }\end{array}$ \\
\hline $\begin{array}{l}\text { Nakajima } \\
\text { et al. } 1999 \\
\text { [2] }\end{array}$ & 21 & $\mathrm{~F}$ & $\begin{array}{l}\text { Systemic lupus } \\
\text { erythematosus; } \\
\text { corticosteroids }\end{array}$ & Pleura & Pleural fluid & $\begin{array}{l}\text { Pleural drainage + } \\
\text { intrapleural IMP + } \\
\text { Mino + TMP-SMX }\end{array}$ & No \\
\hline
\end{tabular}




\section{Cureus}

Torres et

al. 2000

NA NA CLL

Lung, pleura

Pleural fluid

NA

NA

[3]

Torres et

al. 2000

Lung, pleura

Pleural fluid,

sputum

SMX

No

[3]

Torres et

al. 2000

Lung, pleura, brain

Pleural fluid

Pleural drainage +

Yes

[3]

Ando et al.

2001 [4] $69 \quad$ F $\quad$ ITP; corticosteroids

Pleura

Therapeutic

Arunthathi

Arunthathi NA M Corticosteroids,

et al. [5]

thalidomide

Pleura

Severo et

al. $2005 \quad 75 \quad$ M $\quad$ Corticosteroids

[6]

$\begin{array}{llll}\text { Rivero et } & & & \begin{array}{l}\text { Heart transplantation; } \\ \text { corticosteroids, } \\ \text { al. 2008 } 42 \quad \text { M } \\ \text { cyclosporine, and } \\ \text { mycophenolate mofetil }\end{array}\end{array}$

Lung, pleura, thyroid,

heart, kidneys, brain,

bone, lumbosacral soft

tissue

TMP-SMX

Yes

thyroid,

thoracentesis + IMP No

+ TMP-SMX + Mino

Pleural fluid $\quad$ AMK + Mino

NA

Pleura, pericardium,

brain

Pleural fluid,

Pleural and

pericardial pericardial drainages

+ TMP-SMX + IMP + No

fluid

$\mathrm{AMK}+$ linezolid

Parande

et al. $201027 \quad M$

Lung, pleura

Pleural fluid, Pleural drainage +

sputum

TMP-SMX + AMK

Yes

[8]

Budzik et

al. 2012

Intraarticular

[9]

corticosteroids

Knee joint, lung, pleura

Synovial fluid, blood, lung

TMP-SMX

Yes

Ishiguro et
al. 2017
82 M Diabetes mellitus

[10]

Pleura, lung, knee

Pleural fluid,

Pleural and joint

blood,

drainages + Amp-

synovial fluid

sulb + Mino + IMP +

No

Levo

Canouï et

Hematopoietic stem cell

al. 2017

transplantation;

[11]

corticosteroids,

Pleural fluid,

Pleural drainage +

Pleura, lung

pleural

MER + AMK +

biopsy, BAL doxycycline

Huang et

al. $2019 \quad 56 \quad M \quad N A$

[12]

Pleura, lung

Pleural fluid

NA

NA

Huang et

al. $2019 \quad 76 \quad M \quad N$

[12]

Pleura, lung

Pleural fluid

NA

NA

Nasri et al.

2019 [13]

91 M Astrocytoma

Meninges, lung, pleura

Cerebrospinal

TMP-SMX + IMP

Yes

Zayet et

al. $2020 \quad 68 \quad$ M $\quad$ Corticosteroids

Pleura, lung, brain

Pleural fluid,

Pleural drainage +

[14]

BAL

Amox-clav + IMP +

TMP-SMX

\section{TABLE 1: Previous cases of pleural empyema by $\mathbf{N}$. farcinica reported in the literature}

AG, aminoglycoside; AMK, amikacin; Amox-clav, amoxicillin-clavulanate; Amp-sulb, ampicillin-sulbactam; BAL, bronchoalveolar lavage; CIP, ciprofloxacin; CLL, chronic lymphocytic leukemia; CIP, ciprofloxacin; F, female; HIV, human immunodeficiency virus; IMP, imipenem-cilastatin; ITP, immune thrombocytopenic purpura; Levo, levofloxacin; M, male; MER, meropenem; Mino, minocycline; NA, not available; SMX, sulfamethoxazole; TMP-SMX, trimethoprim/sulfamethoxazole 
Nocardiosis mostly affects patients with impaired cell-mediated immunity, as exemplified by these two new observations where the infection developed in the context of a renal transplant recipient under immunosuppressive therapy and advanced cirrhosis, respectively. In a retrospective compilation of 53 patients with $N$. farcinica infections up to the year $1999,85 \%$ had predisposing factors, among which the most frequent was the chronic use of corticosteroids [3]. In fact, at least half of the patients with a nocardial pleural infection listed in Table 1 had a history of corticosteroid treatment.

Pneumonia, brain abscesses and skin infections are the major clinical presentations of $N$. farcinica infection, though in nearly one-third of the cases the disease disseminates, particularly to the central nervous system [3]. Other infections, such as aspergillosis, CMV disease (Case 1) and gram-negative bacteria, may occur concomitantly to nocardiosis [15]. In pulmonary nocardiosis, findings on chest imaging may be variable and include solitary or multiple nodules (Case 1), as well as multifocal consolidations or ground-glass opacities (Cases 1 and 2). Cavitation is usually restricted to immunocompromised patients [15]. Sometimes, the disease may initially resemble tuberculosis, particularly if upper lung lobes are involved and weakly acidfast filaments are seen on respiratory samples. Nocardia filaments may or may not be acid-fast. Although Nocardia may grow in most routine bacterial, fungal and mycobacterial media, the laboratory should be notified of this possibility in order to use selective media (e.g., modified Thayer-Martin, Columbia blood agar). In one review series, the median time required for the isolation of $N$. farcinica in various samples was four days, but growth may take several weeks [3]. If available, molecular diagnostics (e.g., 16S RNA gene sequencing) may allow the identification and speciation of Nocardia isolates.

Two-thirds of pleural infections by $N$. farcinica reported in the literature were managed with tube thoracostomy or therapeutic thoracentesis, in addition to antibiotics (Table 1), as is generally indicated in patients with positive pleural fluid cultures [16]. Antibiotic susceptibility testing is mandatory because treatment should be based on it. According to large series, $N$. farcinica is uniformly susceptible to linezolid and amikacin, commonly susceptible to imipenem and amoxicillin-clavulanate, variably susceptible to TMP-SMX, usually resistant to ciprofloxacin, and typically resistant to third-generation cephalosporins, minocycline and aminoglycosides other than amikacin (Table 2) [1,17-19].

\begin{tabular}{|c|c|c|c|c|c|c|c|c|c|c|}
\hline Country [ref.] & No. of isolates & TMP-SMX & IMP & AMK & Linezolid & Mino & Amox-clav & Cefotaxime & Ceftriaxone & CIP \\
\hline Spain [1] & 128 & $45.3 \%$ & $3.9 \%$ & $1.6 \%$ & $3.1 \%$ & $89.1 \%$ & $18 \%$ & $54.7 \%$ & - & $48.4 \%$ \\
\hline France [17] & 149 & $4 \%$ & $23 \%$ & $1.4 \%$ & $0 \%$ & $12.8 \%$ & $20.1 \%$ & $79.7 \%$ & $80.5 \%$ & $41.9 \%$ \\
\hline USA [18] & 105 & $80 \%$ & $25 \%$ & $0 \%$ & $0 \%$ & $79 \%$ & $10 \%$ & & $93 \%$ & $72 \%$ \\
\hline USA [19] & 319 & $1 \%$ & $17 \%$ & $0 \%$ & $0 \%$ & $93 \%$ & $4 \%$ & - & $97 \%$ & $51 \%$ \\
\hline \multicolumn{11}{|c|}{$\begin{array}{l}\text { TABLE 2: Antimicrobial } \\
\text { different series }(n>100)\end{array}$} \\
\hline \multicolumn{11}{|c|}{$\begin{array}{l}\text { Amox-clav, amoxicillin-clavulanate; AMK, amikacin; CIP, ciprofloxacin; IMP, imipenem-cilastatin; Mino, minocycline; USA, United States of America; } \\
\text { TMP-SMX, trimethoprim/sulfamethoxazole }\end{array}$} \\
\hline
\end{tabular}

Suggested initial regimens for pleuropulmonary nocardiosis usually include the combination of TMP-SMX $(15 \mathrm{mg} / \mathrm{Kg} /$ day of the TMP component IV/po divided in 2-4 doses) plus imipenem (500 mg IV q6h), with the option to add amikacin (7.5 mg/Kg IV q12 h) in severe infections [20]. After 3-4 weeks of intravenous therapy and documented clinical improvement, patients may be switched to oral monotherapy. Duration of antibiotic treatment is generally long (6-12 months). Although these guidelines apply to nocardiosis in general, once the Nocardia species is identified and susceptibility testing results are available, the antibiotic regimen must be adapted. We suggest the combination of imipenem and amikacin for the induction therapy of $N$. farcinica infections. Although linezolid seems an attractive option, its use for more than a few weeks is normally precluded by the risk of hematologic toxicity (Case 2) and neurotoxicity. The mortality of $N$. farcinica pleural infections is not negligible, with more than one-third of fatalities occurring among the reviewed patients (Table 1). To reduce mortality, an early diagnosis and prompt initiation of adequate antibiotic treatment are imperative.

\section{Conclusions}

Pleural infection by $N$. farcinica is rare, with only 16 previously reported cases prior to the new ones exposed herein. This condition should be suspected in immunocompromised subjects with pleural effusions and pulmonary nodules/consolidations. Pleural fluid is an optimal specimen for the isolation of the microorganism. In patients with severe disease or immunocompromise, combination empirical therapy $(\geqslant 2$ drugs) is initially warranted. In particular, consideration should be given to the use of amikacin, imipenem and linezolid. 


\section{Additional Information \\ Disclosures}

Human subjects: Consent was obtained or waived by all participants in this study. NA issued approval NA. Conflicts of interest: In compliance with the ICMJE uniform disclosure form, all authors declare the following: Payment/services info: All authors have declared that no financial support was received from any organization for the submitted work. Financial relationships: All authors have declared that they have no financial relationships at present or within the previous three years with any organizations that might have an interest in the submitted work. Other relationships: All authors have declared that there are no other relationships or activities that could appear to have influenced the submitted work.

\section{References}

1. Valdezate S, Garrido N, Carrasco G, Medina-Pascual MJ, Villalón P, Navarro AM, Saéz-Nieto JA: Epidemiology and susceptibility to antimicrobial agents of the main Nocardia species in Spain . J Antimicrob Chemother. 2017, 72:754-61. 10.1093/jac/dkw489

2. Nakajima A, Taniguchi A, Tanaka M, et al.: [A case of systemic lupus erythematosus complicated by Nocardia farcinica]. (Article in Japanese). Kansenshogaku Zasshi. 1999, 73:477-81.

10.11150/kansenshogakuzasshi1970.73.477

3. Torres OH, Domingo P, Pericas R, Boiron P, Montiel JA, Vázquez G: Infection caused by Nocardia farcinica: case report and review. Eur J Clin Microbiol Infect Dis. 2000, 19:205-12. 10.1007/s100960050460

4. Ando T, Usa T, Ide A, et al.: Pulmonary nocardiosis associated with idiopathic thrombocytopenic purpura . Intern Med. 2001, 40:246-9. 10.2169/internalmedicine.40.246

5. Arunthathi S, Ebenezer G, Daniel E, Sugumaran ST: Nocardia farcinica pleuritis in a lepromatous patient with severe necrotizing reaction: an unusual presentation. Int J Lepr Other Mycobact Dis. 2001, 69:104-7.

6. Severo CB, Oliveira Fde M, Cunha L, Cantarelli V, Severo LC: Disseminated nocardiosis due to Nocardia farcinica: diagnosis by thyroid abscess culture. Rev Inst Med Trop Sao Paulo. 2005, 47:355-8. 10.1590/s003646652005000600009

7. Rivero A, García-Lázaro M, Pérez-Camacho I, Natera C, del Carmen Almodovar M, Camacho A, TorreCisneros J: Successful long-term treatment with linezolid for disseminated infection with multiresistant Nocardia farcinica. Infection. 2008, 36:389-91. 10.1007/s15010-008-7236-7

8. Parande MV, Shinde RS, Mantur BG, Parande AM, Chandrashekhar MR, Aralikatti PS, Palled E: A fatal case of empyema thoracis by Nocardia farcinica in an immunocompromised patient. Indian J Med Microbiol. 2010, 28:390-2. 10.4103/0255-0857.71831

9. Budzik JM, Hosseini M, Mackinnon AC Jr, Taxy JB: Disseminated Nocardia farcinica: literature review and fatal outcome in an immunocompetent patient. Surg Infect (Larchmt). 2012, 13:163-70. 10.1089/sur.2011.012

10. Ishiguro T, Yoshioka H, Kawai S, Katsumata SI, Gonoi T, Takayanagi N: A case of empyema and septic arthritis due to Nocardia farcinica. Clin Case Rep. 2017, 5:1976-9. 10.1002/ccr3.1228

11. Canouï E, Blanc K, Loubinoux J, et al.: The value of molecular techniques to diagnose Ureaplasma urealyticum and Nocardia farcinica pleuropneumonia in a patient with diffuse large B-cell lymphoma. Int J Infect Dis. 2017, 64:93-5. 10.1016/j.ijid.2017.09.015

12. Huang L, Chen $\mathrm{X}, \mathrm{Xu} \mathrm{H}$, et al.: Clinical features, identification, antimicrobial resistance patterns of Nocardia species in China: 2009-2017. Diagn Microbiol Infect Dis. 2019, 94:165-72. 10.1016/j.diagmicrobio.2018.12.007

13. Nasri E, Fakhim H, Barac A, Yousefi S, Aghazade K, Boljevic D, Mardani M: Nocardia farcinica meningitis in a patient with high-grade astrocytoma. J Infect Dev Ctries. 2019, 13:854-7. 10.3855/jidc.11582

14. Zayet S, Lang S, Ben Abdallah Y, Klopfenstein T, Gendrin V: Asymptomatic cerebral abscesses after pleuropulmonary Nocardia farcinica infection. New Microbes New Infect. 2020, 38:100808. 10.1016/j.nmni.2020.100808

15. Steinbrink J, Leavens J, Kauffman CA, Miceli MH: Manifestations and outcomes of nocardia infections: Comparison of immunocompromised and nonimmunocompromised adult patients. Medicine (Baltimore). 2018, 97:e12436. 10.1097/MD.0000000000012436

16. Porcel JM: Minimally invasive treatment of complicated parapneumonic effusions and empyemas in adults . Clin Respir J. 2018, 12:1361-6. 10.1111/crj.12730

17. Lebeaux D, Bergeron E, Berthet J, et al.: Antibiotic susceptibility testing and species identification of Nocardia isolates: a retrospective analysis of data from a French expert laboratory, 2010-2015. Clin Microbiol Infect. 2019, 25:489-95. 10.1016/j.cmi.2018.06.013

18. Uhde KB, Pathak S, McCullum I Jr, et al.: Antimicrobial-resistant nocardia isolates, United States, 19952004. Clin Infect Dis. 2010, 51:1445-8. 10.1086/657399

19. Hamdi AM, Fida M, Deml SM, Abu Saleh OM, Wengenack NL: Retrospective analysis of antimicrobial susceptibility profiles of Nocardia species from a tertiary hospital and reference laboratory, 2011 to 2017. Antimicrob Agents Chemother. 2020, 64:e01868-19. 10.1128/AAC.01868-19

20. The Sanford Guide to Antimicrobial Therapy 2020. Gilbert DN, Chambers HF, Saag MS, Pavia AT (ed): Antimicrobial Therapy, Inc, Sperryville, VA; 2020. 